\title{
H3K36 Methylation in Neural Development and Associated Diseases
}

\author{
Mattia Zaghi ${ }^{1}$, Vania Broccoli ${ }^{1,2 *}$ and Alessandro Sessa ${ }^{1 *}$ \\ ${ }^{1}$ Stem Cell and Neurogenesis Unit, Division of Neuroscience, San Raffaele Scientific Institute, Milan, Italy, ${ }^{2}$ Concilio Nazionale \\ Delle Ricerche (CNR), Instituto di Neuroscienze, Milan, Italy
}

Post-translational methylation of $\mathrm{H} 3$ lysine $36(\mathrm{H} 3 \mathrm{~K} 36)$ is an important epigenetic marker that majorly contributes to the functionality of the chromatin. This mark is interpreted by the cell in several crucial biological processes including gene transcription and DNA methylation. The homeostasis of H3K36 methylation is finely regulated by different enzyme classes which, when impaired, lead to a plethora of diseases; ranging from multi-organ syndromes to cancer, to pure neurological diseases often associated with brain development. This mini-review summarizes current knowledge on these important epigenetic signals with emphasis on the molecular mechanisms that (i) regulate their abundance, (ii) are influenced by H3K36 methylation, and (iii) the associated diseases.

Edited by:

Hehuang Xie,

Virginia Tech, United States

Reviewed by:

Hiroshi Kimura,

Tokyo Institute of Technology,

Japan

Ola Hermanson,

Karolinska Institutet, Sweden

*Correspondence:

Vania Broccoli

broccoli.vania@hsr.it

Alessandro Sessa

sessa.alessandro@hsr.it

Specialty section:

This article was submitted to Epigenomics and Epigenetics,

a section of the journal

Frontiers in Genetics

Received: 26 September 2019

Accepted: 25 November 2019

Published: 09 January 2020

Citation:

Zaghi M, Broccoli V and Sessa A (2020) H3K36 Methylation in

Neural Development and

Associated Diseases.

Front. Genet. 10:1291.

doi: 10.3389/fgene.2019.01291
Keywords: H3K36, histone methyl transferase (HMT), neurodevelopment, SET - Su(var)3-9 and 'Enhancer of zeste', DNA metyltransferases (Dnmts)

\section{INTRODUCTION}

Post-translational modifications of histones are one of the most relevant and best studied mechanisms of epigenetic control used by the cell. Among them, acetylation and methylation of lysine (K) within N-terminals (or tails) of histones (mainly H3) have risen to fame by defining the topological distribution of active and inactive regions in the genome.

High levels of methylation are described at H3K4, K9, K27, K36, K79, each of them having different roles in determining functional features of the chromatin. Methylations of H3K9 and H3K27 are generally described as repressive markers, whereas H3K4, H3K36, H3K79 usually designate regions of active chromatin (Black et al., 2012).

Recently, H3K36 methylation has gained a lot of interest because of its role in several key cellular processes and subsequently many human pathologies. H3K36 methylation has been found to be involved in transcription and splicing regulation (Wang et al., 2007; Edmunds et al., 2007; Pradeepa et al., 2012; Shin et al., 2014), DNA damage response (Pai et al., 2014; Pfister et al., 2014), DNA methylation and dosage compensation (Larschan et al., 2007) among others.

In contrast to acetylation, where only one acetyl group can be inserted, lysine methylation can occur on three different levels, where one, two, or three moieties (mono-, di-, or tri-methylation) can be added to the residue. Each state possibly represents a different epigenetic mark within the socalled epigenetic 'code' (Turner, 2007). H3K36 mono-methylation (H3K36me1) is considered an intermediate modification, apparently without any significant role, whereas different role and distributions have been demonstrated for both di- (H3K36me2) and tri-methylation (H3K36me3); 
$\mathrm{H} 3 \mathrm{~K} 36 \mathrm{me} 3$ is present in gene bodies while $\mathrm{H} 3 \mathrm{~K} 36 \mathrm{me} 2$ is found in intergenic regions, both within lightly packed chromatin. Mass spectrometry analyses of histone modifications have estimated the relative abundances across different organs, revealing that the H3K36 either un-methylated or dimethylated in $\mathrm{K} 36$ are the most abundant spanning between $20 \%$ to $50 \%$ each while the mono-methyl form and the completely saturated proteins are rare with H3K36me3 that reach the 5\% of total $\mathrm{H} 3$ (Yu et al., 2016; Li et al., 2019). Notably, H3 labeled with K36me2 showed high turnover rate compared to the other forms (Zee et al., 2010).

Much has been done in recent years to investigate the specific molecular players involved in H3K36 methylation. Still, a lot of questions remain open regarding the biological meaning of these marks, conveyed by their specific location, as well as the molecular machinery involved in their generation, removal, or interpretation.

In this review, we will provide an overview of recent discoveries and introduce the concept that H3K36 methylation might represent the epigenetic master regulator of euchromatin function. We will put emphasis on developmental disorders in which the alteration of these epigenetic marks has been shown lead to neurological symptoms.

\section{ENZYMATIC CONTROL OF H3K36 METHYLATION}

$\mathrm{H} 3 \mathrm{~K} 36$ methylation is regulated by several mechanisms that control the distribution of the marks as well as the transduction of their biological meaning. The different molecular players (Supplementary Table S1), which are either highly specific for H3K36 or shared with other residues, may be grouped into three categories; the so-called "writers," which are enzymes that catalyze the methylation reaction, and the "erasers," which perform the opposite function and catalyze the removal of methyl groups, together maintain the right homeostasis between the two states (Figure 1). The third category is comprised by the "readers," which are proteins that are able to recognize and interact with specific modifications, possibly interpreting its message. Most of the writers and erasers of lysine methylation are also readers of the same and/or other modifications, however, there are other proteins for which H3K36 methylation acts as a docking signal that regulates downstream functions or pathways.

\section{Writers}

H3K36 writers are histone methyltransferases (HMTs) that contain a SET (Suppressor of variegation 3-9, Enhancer of Zeste, and Trithorax) domain and use S-adenosylmethionine to add methyl groups to histones (or other proteins) (Dillon et al., 2005). H3K36 methylation is an evolutionary conserved process, however, in yeast, only one enzyme-HMT Set2 (SET domain containing protein-2)-carries out each step from mono- to tri-methylation (Krogan et al., 2003; Xiao et al., 2003); in higher eukaryotes, the different steps required to reach full methylation are catalyzed by several enzymes. Most of these enzymes methylate up until a state of di-methylation whereas only two members are able to catalyze the last step to achieve the tri-methylated state (Figure 1).

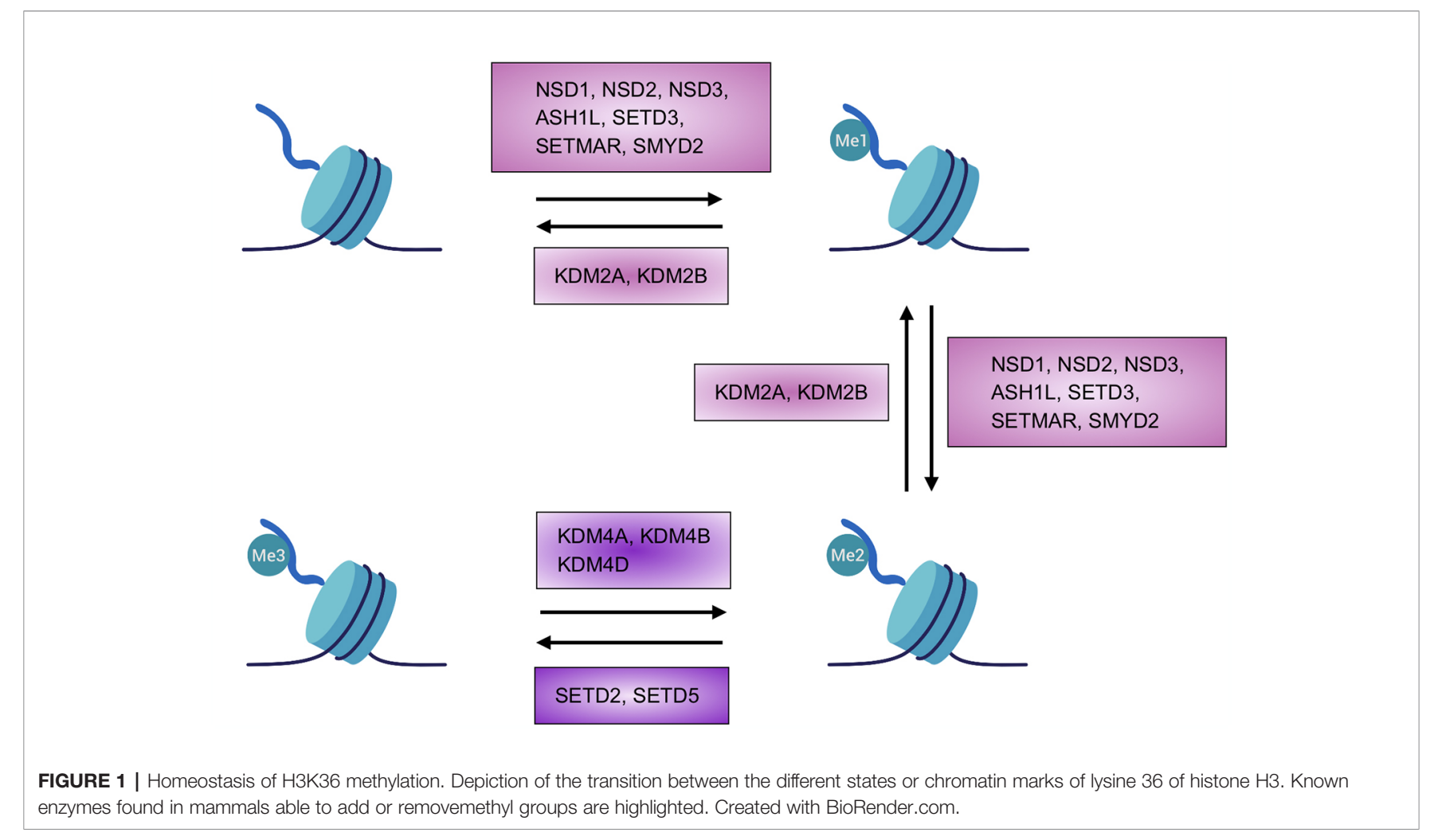


NSD1 (nuclear receptor SET domain-containing protein 1), initially described as nuclear steroid hormone receptor (Huang et al., 1998), has been shown to catalyze H3K36 and H4K20 methylation (Rayasam et al., 2003). Recent studies have restricted its specificity to the di-methylation of H3K36 thanks to experiments performed on purified nucleosomes ( $\mathrm{Li}$ et al., 2009; Qiao et al., 2011). Notably, its absence results in a reduction in all three states of histone methylation, demonstrating the critical role of NSD1 activity even in the trimethylation step that is carried out by other enzymes, probably as supplier of the right amount of substrate for subsequent reaction (Lucio-Eterovic et al., 2010).

Of the same family, NSD2, first identified due to its involvement in chromosomal deletion, causes WolfHirschhorn syndrome (WHS) when mutated (Stec et al., 1998). NSD2 exists in two main isoforms, one catalytically active and the other without the SET domain resulting in an inactive form of the enzyme (Stec et al., 1998). As for NSD1, NSD2 can potentially catalyze the mono- and the di-methylation of H3K36 (Martinez-Garcia et al., 2011; Morishita et al., 2014), although recent studies suggest its preference to perform dimethylation instead of mono-methylation (Qiao et al., 2011; Poulin et al., 2016). The mechanism of action of NSD2 is based on the recognition of regions in which $\mathrm{H} 3 \mathrm{~K} 36$ is already dimethylated thanks to its PWWP (Pro-Trp-Trp-Pro) domain, which stabilizes the protein on the chromatin and directs methyltransferase activity to adjacent regions of chromatin. Thus, in contrast to NSD1, NSD2 functions more as a propagator of methylation rather than a de novo methyltransferase (Waggoner et al., 2005; Kuo et al., 2011; Martinez-Garcia et al., 2011; Morishita et al., 2014; Sankaran et al., 2016).

NSD3 was identified by searching genes with sequence similarity to NSD1 and NSD2 (Angrand et al., 2001; Stec et al., 2001). NSD3 has been found to be expressed in the brain, heart, and skeletal muscle, and to a lesser degree in the liver and lung (Angrand et al., 2001). Three protein products have been associated with NSD3: long, short, and WHISTLE (WHSC1like 1 isoform 9 with methyltransferase activity to lysine). The long (1437 aa) and short (645 aa) isoforms share the same amino terminal sequence, but the short form lacks the catalytically active SET domain and is only able to bind methylated H3K36, thanks to its PWWP domain (Stec et al., 2001; Vermeulen et al., 2010; Wu et al., 2011). WHISTLE is the shortest isoform (506 aa) that includes an active SET domain. WHISTLE activity, however, is associated with methylation of $\mathrm{H} 3 \mathrm{~K} 4$ and $\mathrm{H} 3 \mathrm{~K} 27$ and thus transcriptional repression (Kim et al., 2006; Allali-Hassani et al., 2014).

Outside of the NSD family there are other enzymes that have been described as able to methylate H3K36 as mono- and dimethyltransferases. Activity has been described for ASH1-like (ASH1L), SETMAR (SET domain and mariner transposase fusion gene-containing), SETD3, and SET and MYND domain-containing 2 (SMYD2). These enzymes do not show high specificity, indeed recognition of other substrates has been demonstrated (Lee et al., 2005; Brown et al., 2006; Tanaka et al., 2007; Abu-Farha et al., 2008). As an example, SMYD2 and
ASH1L can methylate $\mathrm{H} 3 \mathrm{~K} 4$, with the latter able to modify also H4K20 (Huang et al., 2006; Gregory et al., 2007).

Up until recently, the only enzyme known to tri-methylate $\mathrm{H} 3$ was SETD2 (Edmunds et al., 2007). SETD2 contains a SET domain and, as for the yeast ortholog, Set2, retains the ability to interact with the large subunit B1 of RNA polymerase II (RNAPII) (Kizer et al., 2005). Intriguingly, the association of SETD2-RNAPII is critical both for HMT activity of SETD2 and for the correct travelling of RNAPII during the elongation phase (Wagner and Carpenter, 2012; McDaniel and Strahl, 2017). However, residual H3K36me3 levels have been reported upon genetic loss of Setd2 in multiple systems (Hu et al., 2010; Pfister et al., 2014; Zhang et al., 2014).

Indeed, we were able for the first time to describe that another SET containing protein, SETD5, can methylate H3K36, both in vitro and in vivo, up to the tri-methylated form (Sessa et al., 2019) (Figure 1). We verified that SETD5, as SETD2, has the capacity to facilitate transcriptional processivity even without direct binding to RNAPII (Sessa et al., 2019), however, further work is needed to clarify the characteristics of this "new" H3K36 HMT.

\section{Erasers}

To maintain a proper control and balance between methylated/ un-methylated states, enzymes (KDMs, Lysine histone demethylases) that can remove post-translational modifications from specific residues, including $\mathrm{H} 3 \mathrm{~K} 36$, are necessary. These enzymes belong to Jumonji family since they contain an essential JmjC catalytic domain (Whetstine et al., 2006; Crona et al., 2013).

In yeast there are two proteins which are able to erase $\mathrm{H} 3 \mathrm{~K} 36$ methylation, Jhd1 (KDM2) and Rph1 (KDM4) (He et al., 2008; Crona et al., 2013), while in mammals, the demethylation of $\mathrm{H} 3 \mathrm{~K} 36$ is performed by two protein families, KDM2A/2B (orthologs of Jhd1) and KDM4A/4B/4D (Rph1) (Figure 1). Specifically, H3K36me1-me2 demethylation is performed by KDM2A/2B (Tsukada et al., 2006) while KDM4A/4B/4D has specificity for $\mathrm{H} 3 \mathrm{~K} 36 \mathrm{me} 3$, but is also able to act on $\mathrm{H} 3 \mathrm{~K} 9 \mathrm{me} 2 /$ me3 (Cloos et al., 2006; Klose et al., 2006).

\section{Readers}

As for every histone modification, H3K36 methylation is essential to orchestrate nucleosome functions within chromatin. In order to execute this function, H3K36 signatures must be recognized by chromatin cofactors. In the case of $\mathrm{H} 3 \mathrm{~K} 36 \mathrm{me}$, reader proteins often contain one of the following domains: tudor, PWWP, or chromodomain (Li et al., 2019). As mentioned before, many epigenetic writers may also function as readers to ensure either the completion of residue methylation or the spread of a different methylation state to nearby residues.

In addition to the already cited roles of the NSD proteins, many other proteins contain PWWP domains, including those able to methylate DNA (DNMT3A and 3B), those involved in DNA repair (MSH6, LEDGF) and the H3.3K36m3 specific reader, ZMYND11 (Li et al., 2019). PHF1 and PHF19 contain tudor domains and are responsible for facilitating the entrance of Polycomb repressive complex 2 (PRC2) in H3K36me marked regions (Cai et al., 2013). 
The H3K36me3 reader, MRG15, contains a chromodomain and can interact with other epigenetic modifiers, such as the histone demethylase $\mathrm{KDM} 5 \mathrm{~B}$, to promote $\mathrm{H} 3 \mathrm{~K} 4 \mathrm{me} 3$ removal from intragenic regions (Hayakawa et al., 2007).

\section{BIOLOGICAL ROLES OF H3K36 METHYLATION}

Experimental evidence obtained from different experimental systems suggests that $\mathrm{H} 3 \mathrm{~K} 36$ methylation is a major central epigenetic modification that orchestrates the function of euchromatin. Indeed, while euchromatin has been widely associated with histone acetylation, which is physically associated with chromatin opening, $\mathrm{H} 3 \mathrm{~K} 36 \mathrm{me}$ has a clear role in defining important regions of active chromatin.

This concept is especially supported by the role of $\mathrm{H} 3 \mathrm{~K} 36$ methylation in the regulation of transcription and cotranscriptional processes (Wang et al., 2007; Edmunds et al., 2007; Pradeepa et al., 2012; Shin et al., 2014; Sessa et al., 2019) and, by association, with DNA methylation (Baubec et al., 2015; Weinberg et al., 2019) (Figure 2). Furthermore, H3K36 methylation has been demonstrated to be essential for regulated segregation of heterochromatin regions, via the control of CBP/p300 localization (Cabianca et al., 2019).

In this section, we will dissect the molecular role of this epigenetic modification, and thus the biological consequences in having or not the H3K36me for a cell.

\section{H3K36 Methylation and Transcription}

$\mathrm{H} 3 \mathrm{~K} 36 \mathrm{me} 3$ is found in the body of transcriptionally active genes, a genomic landscape where finely tuned and intimately interconnected mechanisms occur. In these regions, RNA elongation, splicing, and inhibition of the generation of spurious intragenic transcripts are coordinated to ensure effective transcriptional processes. The relationship between $\mathrm{H} 3 \mathrm{~K} 36 \mathrm{me}$ and transcription was demonstrated first because it was found that Set2, thanks to its SRI domain, is able to interact with the phosphorylated CTD (C-terminus domain) of the active RNAPII. The abrogation of this interaction via the removal or mutation of the SRI domain causes not only a strong alteration in transcriptional elongation, but also disrupts the methyltransferase activity of Set2 (Wagner and Carpenter, 2012; McDaniel and Strahl, 2017). The relationship between RNAPII travelling and $\mathrm{H} 3 \mathrm{~K} 36 \mathrm{me}$ is important also to limit the initiation of aberrant intragenic transcription along active genes, which in yeast relies upon local deacetylation activity (Carrozza et al., 2005) and remain elusive in mammals (Carvalho et al., 2013). Moreover, inclusion/exclusion of exons has been associated with intragenic $\mathrm{H} 3 \mathrm{~K} 36 \mathrm{me} 3$ levels in gene bodies through the recruitment of $\mathrm{H} 3 \mathrm{~K} 36 \mathrm{me} 3$ readers (MRG15 and ZYMIND11) that directly modulate the activity of splicing factors (Luco et al., 2010; Guo et al., 2014).

In higher eukaryotes, both $\mathrm{H} 3 \mathrm{~K} 36 \mathrm{me} 2$ and me3 have been described to regulate transcription. In particular, H3K36me2 in gene bodies is enriched in expressed genes, positively correlating its presence with transcription levels, even though it seemed not essential (Bannister et al., 2005; Kuo et al., 2011). NSD2 overexpressing tumor cells showed a de novo oncogenic program caused by the re-location of H3K36me2 (Kuo et al., 2011). The safeguard of transcription and co-transcriptional processes, instead, have been associated with SETD2 activity, the only known HMT able to achieve H3K36me3 (Luco et al., 2010) (Wagner and Carpenter, 2012). Recent evidence from our group suggest that the paralog protein, SETD5, is able to trimethylate H3K36 (Sessa et al., 2019). Accordingly, we have

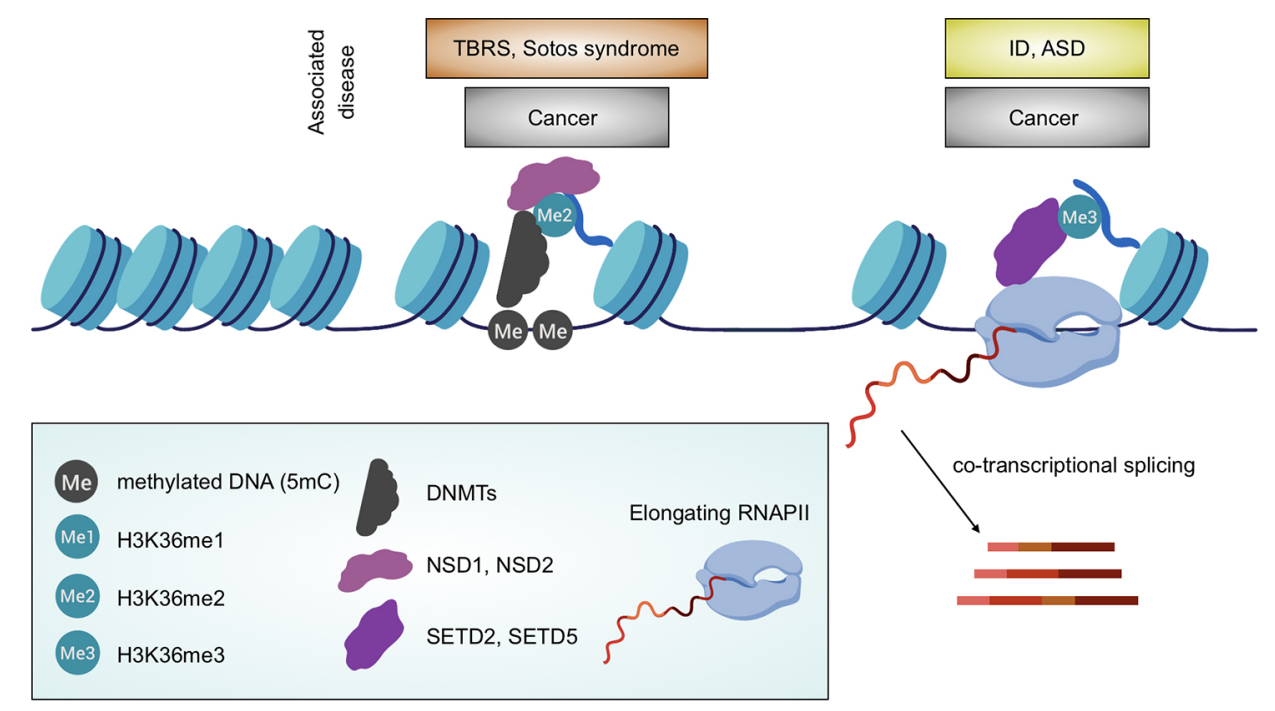

FIGURE 2 | Association between H3K36 methylation and biological processes. Depiction of the linkage between H3K36 HMTs with either DNA methylation distribution or transcription including co-transcriptional processes (RNA splicing is shown). Associated diseases are also highlighted. Created with BioRender.com. 
shown that a low level of Setd5 in the murine nervous system causes a decrease of $\mathrm{H} 3 \mathrm{~K} 36 \mathrm{me} 3$, which results in global perturbation of the transcriptome. This was particularly evident for highly transcribed genes, which displayed reduced transcriptional processivity and a higher percentage of aberrant splicing events (Sessa et al., 2019). Thus, H3K36me3 dysregulation, due to the impairment of either SETD2 or SETD5, underlines the central role of H3K36me3 in defining the epigenetic landscape in gene bodies that controls the stability and activity of euchromatin. As such, fine tuning H3K36me distribution and quantity is vital for the cell to such an extent that even a slight change in methylation is detrimental on many levels, as testified by the related occurrence of many diseases (see later).

\section{H3K36 Methylation and DNA Methylation}

Recent work has demonstrated how the process of DNA methylation is tightly regulated and linked with both H3K36me2 and me3 (Baubec et al., 2015; Morselli et al., 2015; Weinberg et al., 2019). Experimental evidence suggests that the binding profile and consequently the activity of the DNMTs is influenced by the presence of $\mathrm{H} 3 \mathrm{~K} 36 \mathrm{me} 2 / 3$, findings in line with their activity as $\mathrm{H} 3 \mathrm{~K} 36 \mathrm{me}$ reader. Using mouse embryonic stem cells, it has been demonstrated how the activity of SETD2, and thus the level of $\mathrm{H} 3 \mathrm{~K} 36 \mathrm{me}$, are essential for the localization and activity of DNMT3B (Baubec et al., 2015). Indeed, both Setd2 KO and mutation of the PWWP domain in DNMT3B impaired DNA methylation (Baubec et al., 2015). More recently, it has been proposed that the portion of the genome that is $\mathrm{H} 3 \mathrm{~K} 36 \mathrm{me} 2$ positive is highly enriched (75\%) in CpG methylation (Weinberg et al., 2019). Furthermore, these regions are also marked by H3K4me1 and H3K27ac, highlighting how H3K36me2 defines active regions of euchromatin, especially in intergenic regions. The authors in this work also specified that DNMT3B activity depends on H3K36me3 whilst DNMT3A is associated with regions enriched in $\mathrm{H} 3 \mathrm{~K} 36 \mathrm{me}$, usually marking intergenic regions, thus demonstrating that different $\mathrm{H} 3 \mathrm{~K} 36$ methylation states precisely control methylation levels in different chromatin regions. Nsd1/2 knock-out in embryonic stem cells causes a total depletion of $\mathrm{H} 3 \mathrm{~K} 36 \mathrm{me} 2$ within intergenic regions and consequent loss of binding and activity of DNMT3A which instead is repositioned across DNMT3B domains. Taken together, these findings demonstrate that there is a fine crosstalk between DNA and H3K36 methylation, which orchestrates the distribution and activity of different DNA methyltransferases in euchromatin.

\section{H3K36 METHYLATION IN NEURODEVELOPMENTAL DISEASES}

Not surprisingly, alterations in the H3K36 methylation levels are associated with different athologies, including many types of cancer and neurological disorders of developmental origin (Figure 2). From a genetic view point, these alterations may be due to either mutations in KTMs or KDMs, or even due to the substitution of the K36 residue itself (K36M), or nearby residues (e.g. G34V/R) creating so-called onco-histones (Nacev et al., 2019). Additionally, some diseases may be linked with H3K36me, despite no differences in the level of markers, because of an impairment in the downstream interpretation of these epigenetic signals, e.g. due to mutations in genes encoding for $\mathrm{H} 3 \mathrm{~K} 36 \mathrm{me}$ readers.

Furthermore, the analysis of animal models deficient in specific H3K36 HMTs testify the importance of having the correct levels of the different H3K36me modifications. Indeed, knock-out (KO) mouse models of NSD protein 1 and 2 are both lethal, either very early during development (at embryonic day (E) 6.5) in the case of $N s d 1$ (Rayasam et al., 2003), or at postnatal day (P) 10 for Nsd2 (Nimura et al., 2009).

Lethality is also true for $\mathrm{KO}$ of the two H3K36 trimethyltransferases, where the full Setd $2 \mathrm{KO}$ is viable until E10.5-E11.5 (Hu et al., 2010), and the Setd5 KO is lethal at E9.5 (Osipovich et al., 2016). Lastly, also the H3K36me erasers have emerged as important for neural cell development; in fact, KDM proteins have been found essential for neuronal differentiation, survival, and either the expression or repression of specific genes (e.g. expression of Bdnf, repression of Gfap) (Cascante et al., 2014; Sudo et al., 2016), while KDM8 has been associated with proliferation of Schwann cells controlling the expression of cell-cycle relevant genes (Fuhrmann et al., 2018).

In the following paragraphs, we will describe the different pathologies associated with the aforementioned cellular processes, with a focus on their neurological implications.

\section{H3K36me Pathologies Associated With Splicing Regulation}

The central nervous system is probably the site where the greatest number of alternative splicing events occur; this is even more true in neurons where the difference between each subtype is frequently determined by the expression of different splice isoforms of several key genes (Furlanis et al., 2019).

Mutations in SETD2 gene are associated with cases of autism spectrum disorders (ASD) (Iossifov et al., 2014; Lumish et al., 2015) and with "Sotos like syndrome," an overgrowth disease with cognitive impairment (Luscan et al., 2014). A growing number of evidences link haploinsufficiency of SETD5 to cases of intellectual disability (ID), ASD, and 3p25.3 microdeletion syndrome (Rauch et al., 2012; Kellogg et al., 2013; De Rubeis et al., 2014; Grozeva et al., 2014; Kuechler et al., 2015; Szczałuba et al., 2016; Parenti et al., 2017). Analysis of in vitro and in vivo loss-of-SETD5-function models revealed the importance of the correct level of $\mathrm{H} 3 \mathrm{~K} 36 \mathrm{me} 3$ for the correct structural and functional maturation of the central nervous system (Sessa et al., 2019). Indeed, pathological phenotypes seem to be caused by defects in RNA elongation/RNAPII processivity (Deliu et al., 2018; Sessa et al., 2019) that cause a massive deregulation of co-transcriptional processes, including splicing events (Sessa et al., 2019).

Both NSD1 and NSD2 haploinsufficiency lead to neurodevelopmental syndromes, namely Sotos syndrome and 
WHS, respectively (Kurotaki et al., 2002; Nimura et al., 2009). Strikingly, a percentage of WHS patients is mutated in the transcription elongator factor gene NELFA, inducing a decrease in elongation rates (Yamaguchi et al., 1999). Thus, the association between SETD5-H3K36me3-RNA balance is instructive for the importance of this epigenetic modification in the correct structural and functional maturation of the central nervous system. However, the interconnection of H3K36me levels and co-transcriptional events has probably a broader impact since other devastating diseases, such as several types of cancer, display a correlation between low $\mathrm{H} 3 \mathrm{~K} 36 \mathrm{me} 3$, caused by mutations in either SETD2, or SETD5, or H3 and an impairment in transcriptional fidelity and co-transcriptional mechanisms, such as RNA processing and stability, chimeric RNAs, aberrant cryptic transcripts etc. (Fontebasso et al., 2013; Bueno et al., 2016; Papillon-Cavanagh et al., 2017).

\section{H3K36me Pathologies Associated With DNA Methylation}

Tatton-Brown-Rahman syndrome (TBRS) (Tatton-Brown et al., 2014) and Sotos syndrome (Kurotaki et al., 2002) share many pathological phenotypes, which may be due to the relationship between H3K36 methylation and DNA methylation.

TBRS is caused by mutations in DNMT3A gene, with a proportion of mutations having been found within the PWWP domain which, as described before, allows for the reading of H3K36 methylation. This syndrome is described as an "overgrowth syndrome," which is characterized by distinctive facial appearance, tall stature, mild to severe cognitive deficits, which result in behavioral/psychiatric issues, and some combination of traits typical of ASD (Tatton-Brown et al., 2018).

NSD1-associated Sotos syndrome presents with overgrowth as the main phenotype during the first years of life, with distinctive facial traits and developmental delays characterized by intellectual disability (Waggoner et al., 2005). Individuals with Sotos syndrome can have mild to severe mental retardation, causing behavioral abnormalities and social struggle (Sarimski and Psychologist, 2003). Interestingly, a strong and generalized decrease in DNA methylation levels has been found in blood samples of Sotos syndrome patients (Choufani et al., 2015), as was found in TBRS patients.

The concept that DNA methylation is essential for mammalian brain development and associated human pathologies, notably Rett syndrome (Amir et al., 1999), is not new and has extensively been described (Lister et al., 2013). What is lesser known, however, is how the DNA methylation is finely regulated. Both Sotos and Tatton-Brown-Rahman syndromes, previously discussed, are caused by completely different mutations and yet have major clinical and molecular phenotypes in common; this supports the importance of the intimate and profound connection between H3K36me, distribution of DNMTs and DNA methylation (Figure 2).

Again, even in this case, cancer biology further supports this observation since cases in head and neck squamous cell carcinomas present mutations in NSD1, within or close to the
SET domain, or K36M substitution and remarkable DNA hypomethylation (Papillon-Cavanagh et al., 2017).

\section{CONCLUSIONS}

Histone post-translational modifications of $\mathrm{H} 3 \mathrm{~K} 36$ define at least two widespread epigenetic marks (H3K36me2 and me3) with an extensive role in determining the chromatin landscape and in directing complex biological processes. Some of these best characterized processes include: (i) the control of transcriptional fidelity, meaning the correct execution of transcription and other strictly associated mechanisms, (ii) the control of DNA methylation, (iii) DNA repair, and (iv) the interplay with other epigenetic marks. However, the complexity of $\mathrm{H} 3 \mathrm{~K} 36 \mathrm{me}$ regulation, including the discovery of a new HMT, and the elusive nature of $\mathrm{H} 3 \mathrm{~K} 36 \mathrm{me} 2$ decoration on the genome suggest that many aspects still need to be elucidated in the future. Moreover, less famous and studied modifications of the same residue, as in the mono-methyl form as well as the acetylated version (H3K36ac) (Morris et al., 2007), may hide some neglected functional implications. Since the high correlation between H3K36 modifications and human diseases, more work is required to complete the picture. The community will benefit from the interconnection of the different experimental approaches of biochemistry, structural biology, new in vitro and in vivo model systems as well as from a thorough clinical observation coupled with molecular profiling of patients.

\section{AUTHOR CONTRIBUTIONS}

All authors have contributed to the conception of this article and approved it for publication.

\section{FUNDING}

This work was supported by the Italian Ministry of Health (GR2013-02355540 to AS).

\section{ACKNOWLEDGMENTS}

We apologize to those researchers whose work could not be cited owing to space constraints. We thank Dr. J. Carpenter for the critical reading of the manuscript.

\section{SUPPLEMENTARY MATERIAL}

The Supplementary Material for this article can be found online at: https://www.frontiersin.org/articles/10.3389/fgene.2019. 01291/full\#supplementary-material

SUPPLEMENTARY TABLE 1 | Genes/proteins cited in this mini-review with official names and aliases. 


\section{REFERENCES}

Abu-Farha, M., Lambert, J.-P., Al-Madhoun, A. S., Elisma, F., Skerjanc, I. S., and Figeys, D. (2008). The tale of two domains. Mol. Cell. Proteom 7, 560 LP-56 572. doi: 10.1074/mcp.M700271-MCP200

Allali-Hassani, A., Kuznetsova, E., Hajian, T., Wu, H., Dombrovski, L., Li, Y., et al. (2014). A basic post-set extension of nsds is essential for nucleosome binding in vitro. J. Biomol. Screen 19, 928-935. doi: 10.1177/1087057114525854

Amir, R. E., Van den Veyver, I. B., Wan, M., Tran, C. Q., Francke, U., and Zoghbi., H. Y. (1999). Rett syndrome is caused by mutations in X-linked MECP2, encoding methyl-CpG-binding protein 2. Nat. Genet. 23, 185-188. doi: $10.1038 / 13810$

Angrand, P.-O., Apiou, F., Stewart, A. F., Dutrillaux, B., Losson, R., and Chambon, P. (2001). NSD3, a new set domain-containing gene, maps to $8 \mathrm{p} 12$ and is amplified in human breast cancer cell lines. Genomics 74, 79-88. doi: $10.1006 /$ geno.2001.6524

Bannister, A. J., Schneider, R., Myers, F. A., Thorne, A. W., Crane-Robinson, C., and Kouzarides, T. (2005). Spatial distribution of di- and tri-methyl lysine 36 of histone $\mathrm{H} 3$ at active genes. J. Biol. Chem. 280 (18), 17732-17736. doi: 10.1074/ jbc.M500796200

Baubec, T., Colombo, D. F., Wirbelauer, C., Schmidt, J., Burger, L., Krebs, A. R., et al. (2015). Genomic profiling of DNA methyltransferases reveals a role for DNMT3B in genic methylation. Nature 520, 243-247. doi: 10.1038/ nature14176

Black, J. C., Van Rechem, C., and Whetstine, J. R. (2012). Histone lysine methylation dynamics: establishment, regulation, and biological impact. Mol. Cell. 48, 491-507. doi: 10.1016/j.molcel.2012.11.006

Brown, M. A., Sims, R. J., Gottlieb, P. D., and Tucker, P. W. (2006). Identification and characterization of Smyd2: a split SET/MYND domain-containing histone H3 lysine 36-specific methyltransferase that interacts with the Sin3 histone deacetylase complex. Mol. Cancer. 5, 26. doi: 10.1186/1476-4598-5-26

Bueno, R., Stawiski, E. W., Goldstein, L. D., Durinck, S., De Rienzo, A., Modrusan, Z., et al. (2016). Comprehensive genomic analysis of malignant pleural mesothelioma identifies recurrent mutations, gene fusions and splicing alterations. Nat. Genet. 48, 407-416. doi: 10.1038/ng.3520

Cabianca, D. S., Muñoz-Jiménez, C., Kalck, V., Gaidatzis, D., Padeken, J., Seeber, A., et al. (2019). Active chromatin marks drive spatial sequestration of heterochromatin in C. elegans nuclei. Nature 569, 734-739. doi: 10.1038/ s41586-019-1243-y

Cai, L., Rothbart, S. B., Lu, R., Xu, B., Chen, W. Y., Tripathy, A., et al. (2013). An H3K36 methylation-engaging Tudor motif of polycomb-like proteins mediates PRC2 complex targeting. Mol. Cell 49, 571-582. doi: 10.1016/j.molcel.2012.11.026

Carrozza, M. J., Li, B., Florens, L., Suganuma, T., Swanson, S. K., Lee, K. K., et al. (2005). Histone H3 methylation by Set2 directs deacetylation of coding regions by Rpd3S to suppress spurious intragenic transcription. Cell 123, 581-592. doi: 10.1016/i.cell.2005.10.023

Carvalho, S., Raposo, A. C., Martins, F. B., Grosso, A. R., Sridhara, S. C., Rino, J., et al. (2013). Histone methyltransferase SETD2 coordinates FACT recruitment with nucleosome dynamics during transcription. Nucleic Acids Res. 41, 28812893. doi: $10.1093 /$ nar/gks1472

Cascante, A., Klum, S., Biswas, M., Antolin-Fontes, B., Barnabé-Heider, F., and Hermanson, O. (2014). Gene-specific methylation control of H3K9 and H3K36 on neurotrophic BDNF versus astroglial GFAP genes by KDM4A/C regulates neural stem cell differentiation. J. Mol. Biol. 426 (20), 3467-3477. doi: 10.1016/ j.jmb.2014.04.008

Choufani, S., Cytrynbaum, C., Chung, B. H. Y., Turinsky, A. L., Grafodatskaya, D., Chen, Y. A., et al. (2015). NSD1 mutations generate a genome-wide DNA methylation signature. Nat. Commun. 6, 10207. doi: 10.1038/ncomms10207

Cloos, P. A. C., Christensen, J., Agger, K., Maiolica, A., Rappsilber, J., Antal, T., et al. (2006). The putative oncogene GASC1 demethylates tri- and dimethylated lysine 9 on histone H3. Nature 442, 307-311. doi: 10.1038/nature04837

Crona, F., Dahlberg, O., Lundberg, L. E., Larsson, J., and Mannervik, M. (2013). Gene regulation by the lysine demethylase KDM4A in Drosophila. Dev. Biol. 373, 453-463. doi: 10.1016/j.ydbio.2012.11.011

De Rubeis, S., He, X., Goldberg, A. P., Poultney, C. S., Samocha, K., Cicek, A. E., et al. (2014). Synaptic, transcriptional and chromatin genes disrupted in autism. Nature 515, 209-215. doi: 10.1038/nature13772
Deliu, E., Arecco, N., Morandell, J., Dotter, C. P., Contreras, X., Girardot, C., et al. (2018). Haploinsufficiency of the intellectual disability gene SETD5 disturbs developmental gene expression and cognition. Nat. Neurosci. 21, 1717-1727. doi: $10.1038 / \mathrm{s} 41593-018-0266-2$

Dillon, S. C., Zhang, X., Trievel, R. C., and Cheng, X. (2005). The SET-domain protein superfamily: protein lysine methyltransferases. Genome Biol. 6, 227. doi: 10.1186/gb-2005-6-8-227

Edmunds, J. W., Mahadevan, L. C., and Clayton, A. L. (2007). Dynamic histone H3 methylation during gene induction: $\mathrm{HYPB} / \mathrm{Setd} 2$ mediates all $\mathrm{H} 3 \mathrm{~K} 36$ trimethylation. EMBO J. 27, 406 LP-40 420. doi: 10.1038/sj.emboj.7601967

Fontebasso, A. M., Schwartzentruber, J., Khuong-Quang, D. A., Liu, X. Y., Sturm, D., Korshunov, A., et al. (2013). Mutations in SETD2 and genes affecting histone $\mathrm{H} 3 \mathrm{~K} 36$ methylation target hemispheric high-grade gliomas. Acta Neuropathol. 125, 659-669. doi: 10.1007/s00401-013-1095-8

Fuhrmann, D., Mernberger, M., Nist, A., Stiewe, T., and Elsässer, H. P. (2018). Mizl controls schwann cell proliferation via $\mathrm{H} 3 \mathrm{~K} 36 \mathrm{me} 2$ demethylase $\mathrm{kdm} 8$ to prevent peripheral nerve demyelination. J. Neurosci. 38 (4), 858-877. doi: 10.1523/JNEUROSCI.0843-17.2017

Furlanis, E., Traunmüller, L., Fucile, G., and Scheiffele, P. (2019). Landscape of ribosome-engaged transcript isoforms reveals extensive neuronal-cell-classspecific alternative splicing programs. Nat. Neurosci. 22, 1709-1717. doi: 10.1038/s41593-019-0465-5

Gregory, G. D., Vakoc, C. R., Rozovskaia, T., Zheng, X., Patel, S., Nakamura, T., et al. (2007). Mammalian ash1l is a histone methyltransferase that occupies the transcribed region of active genes. Mol. Cell. Biol. 27, 8466 LP- 8479. doi: 10.1128/MCB.00993-07

Grozeva, D., Carss, K., Spasic-Boskovic, O., Parker, M. J., Archer, H., Firth, H. V., et al. (2014). De novo loss-of-function mutations in SETD5, encoding a methyltransferase in a 3p25 microdeletion syndrome critical region, cause intellectual disability. Am. J. Hum. Genet. 94, 618-624. doi: 10.1016/ j.ajhg.2014.03.006

Guo, R., Zheng, L., Park, J. W., Lv, R., Chen, H., Jiao, F., et al. (2014). BS69/ ZMYND11 reads and connects histone h3.3 lysine 36 trimethylation-decorated chromatin to regulated pre-mrna processing. Mol. Cell 56, 298-310. doi: 10.1016/j.molcel.2014.08.022

Hayakawa, T., Ohtani, Y., Hayakawa, N., Shinmyozu, K., Saito, M., Ishikawa, F., et al. (2007). RBP2 is an MRG15 complex component and down-regulates intragenic histone H3 lysine 4 methylation. Genes Cells 12 (6), 811-826. doi: 10.1111/j.1365-2443.2007.01089.x

He, J., Kallin, E. M., Tsukada, Y., and Zhang, Y. (2008). The H3K36 demethylase Jhdm $1 \mathrm{~b} / \mathrm{Kdm} 2 \mathrm{~b}$ regulates cell proliferation and senescence through p15Ink $4 \mathrm{~b}$. Nat. Struct. Mol. Biol. 15, 1169. doi: 10.1038/nsmb.1499

Hu, M., Sun, X. J., Zhang, Y. L., Kuang, Y., Hu, C. Q., Wu, W. L., et al. (2010). Histone $\mathrm{H} 3$ lysine 36 methyltransferase Hypb/Setd2 is required for embryonic vascular remodeling. Proc. Natl. Acad. Sci. 107, 2956 LP- 2961. doi: 10.1073/ pnas. 0915033107

Huang, N., vom Baur, E., Garnier, J., Lerouge, T., Vonesch, J., Lutz, Y., et al. (1998). Two distinct nuclear receptor interaction domains in NSD1, a novel set protein that exhibits characteristics of both corepressors and coactivators. EMBO J. 17, 3398 LP- 3412. doi: 10.1093/emboj/17.12.3398

Huang, J., Perez-Burgos, L., Placek, B. J., Sengupta, R., Richter, M., Dorsey, J. A., et al. (2006). Repression of p53 activity by Smyd2-mediated methylation. Nature 444, 629-632. doi: 10.1038/nature05287

Iossifov, I., O’Roak, B. J., Sanders, S. J., Ronemus, M., Krumm, N., Levy, D., et al. (2014). The contribution of de novo coding mutations to autism spectrum disorder. Nature 515, 216-221. doi: 10.1038/nature13908

Kellogg, G., Sum, J., and Wallerstein, R. (2013). Deletion of 3p25.3 in a patient with intellectual disability and dysmorphic features with further definition of a critical region. Am. J. Med. Genet. Part A. 161, 1405-1408. doi: 10.1002/ajmg.a.35876

Kim, S. M., Kee, H. J., Eom, G. H., Choe, N. W., Kim, J. Y., Kim, Y. S., et al. (2006). Characterization of a novel WHSC1-associated set domain protein with H3K4 and H3K27 methyltransferase activity. Biochem. Biophys. Res. Commun. 345, 318-323. doi: 10.1016/j.bbrc.2006.04.095

Kizer, K. O., Phatnani, H. P., Shibata, Y., Hall, H., Greenleaf, A. L., and Strahl, B. D. (2005). A novel domain in set2 mediates RNA polymerase II Interaction and couples histone H3 K36 methylation with transcript elongation. Mol. Cell. Biol. 25 , 3305-3316. doi: 10.1128/MCB.25.8.3305-3316.2005 
Klose, R. J., Yamane, K., Bae, Y., Zhang, D., Erdjument-Bromage, H., Tempst, P., et al. (2006). The transcriptional repressor JHDM3A demethylates trimethyl histone H3 lysine 9 and lysine 36. Nature 442 (7100), 312-316. doi: 10.1038/ nature 04853

Krogan, N. J., Kim, M., Tong, A., Golshani, A., Cagney, G., Canadien, V., et al. (2003). Methylation of Histone H3 by Set2 in Saccharomyces cerevisiae Is Linked to Transcriptional Elongation by RNA Polymerase II. Mol. Cell. Biol. 23, 4207-4218. doi: 10.1128/MCB.23.12.4207-4218.2003

Kuechler, A., Zink, A. M., Wieland, T., Lüdecke, H.-J., Cremer, K., Salviati, L., et al. (2015). Loss-of-function variants of SETD5 cause intellectual disability and the core phenotype of microdeletion 3p25.3 syndrome. Eur. J. Hum. Genet., 1-8. doi: 10.1038/ejhg.2014.165

Kuo, A. J., Cheung, P., Chen, K., Zee, B. M., Kioi, M., Lauring, J., et al. (2011). NSD2 links dimethylation of histone $\mathrm{H} 3$ at lysine 36 to oncogenic programming. Mol. Cell. 44, 609-620. doi: 10.1016/j.molcel.2011.08.042

Kurotaki, N., Imaizumi, K., Harada, N., Masuno, M., Kondoh, T., Nagai, T., et al. (2002). Haploinsufficiency of NSD1 causes sotos syndrome. Nat. Genet. 30, 365-366. doi: $10.1038 / \mathrm{ng} 863$

Larschan, E., Alekseyenko, A. A., Gortchakov, A. A., Peng, S., Li, B., Yang, P., et al. (2007). MSL complex is attracted to genes marked by h3k36 trimethylation using a sequence-independent mechanism. Mol. Cell. 28, 121-133. doi: 10.1016/j.molcel.2007.08.011

Lee, S.-H., Oshige, M., Durant, S. T., Rasila, K. K., Williamson, E. A., Ramsey, H., et al. (2005). The SET domain protein Metnase mediates foreign DNA integration and links integration to nonhomologous end-joining repair. Proc. Natl. Acad. Sci. U. S. A 102, 18075 LP-18080. doi: 10.1073/pnas.0503676102

Li, Y., Trojer, P., Xu, C.-F., Cheung, P., Kuo, A., Drury, W. J., et al. (2009). The target of the NSD family of histone lysine methyltransferases depends on the nature of the substrate. J. Biol. Chem. 84, 34283-34295. doi: 10.1074/ jbc.M109.034462

Li, J., Ahn, J. H., and Wang, G. G. (2019). Understanding histone H3 lysine 36 methylation and its deregulation in disease. Cell Mol. Life Sci. 76 (15), 28992916. doi: 10.1007/s00018-019-03144-y

Lister, R., Mukamel, E. A., Nery, J. R., Urich, M., Puddifoot, C. A., Johnson, N. D., et al. (2013). Global epigenomic reconfiguration during mammalian brain development. Science 341 (6146), 1237905. doi: 10.1126/science.1237905

Lucio-Eterovic, A. K., Singh, M. M., Gardner, J. E., Veerappan, C. S., Rice, J. C., and Carpenter., P. B. (2010). Role for the nuclear receptor-binding SET domain protein 1 (NSD1) methyltransferase in coordinating lysine 36 methylation at histone 3 with RNA polymerase II function. Proc. Natl. Acad. Sci. 107, 16952 LP- 16957. doi: 10.1073/pnas.1002653107

Luco, R. F., Pan, Q., Tominaga, K., Blencowe, B. J., Pereira-Smith, O. M., and Misteli., T. (2010). Regulation of alternative splicing by histone modifications. Science 327 (5968), 996-1000. doi: 10.1126/science.1184208

Lumish, H. S., Wynn, J., Devinsky, O., and Chung, W. K. (2015). Brief Report: SETD2 Mutation in a Child with Autism, Intellectual Disabilities and Epilepsy. J. Autism Dev. Disord. 45, 3764-3770. doi: 10.1007/s10803-015-2484-8

Luscan, A., Laurendeau, I., Malan, V., Francannet, C., Odent, S., Giuliano, F., et al. (2014). Mutations in SETD2 cause a novel overgrowth condition. J. Med. Genet. 51, 512-517. doi: 10.1136/jmedgenet-2014-102402

Martinez-Garcia, E., Popovic, R., Min, D.-J., Sweet, S. M. M., Thomas, P. M., Zamdborg, L., et al. (2011). The MMSET histone methyl transferase switches global histone methylation and alters gene expression in $\mathrm{t}(4 ; 14)$ multiple myeloma cells. Blood 117, 211 LP-21 220. doi: 10.1182/blood2010-07-298349

McDaniel, S. L., and Strahl, B. D. (2017). Shaping the cellular landscape with Set2/ SETD2 methylation. Cell Mol. Life Sci. 74 (18), 3317-3334. doi: 10.1007/ s00018-017-2517-x

Morishita, M., Mevius, D., and di Luccio, E. (2014). In vitro histone lysine methylation by NSD1, NSD2/MMSET/WHSC1 and NSD3/WHSC1L. BMC Struct. Biol. 14, 25. doi: 10.1186/s12900-014-0025-x

Morris, S. A., Rao, B., Garcia, B. A., Hake, S. B., Diaz, R. L., Shabanowitz, J., et al. (2007). Identification of histone H3 lysine 36 acetylation as a highly conserved histone modification. J. Biol. Chem. 282 (10), 7632-7640. doi: 10.1074/ jbc.M607909200

Morselli, M., Pastor, W. A., Montanini, B., Nee, K., Ferrari, R., Fu, K., et al. (2015). In vivo targeting of de novo DNA methylation by histone modifications in yeast and mouse. Elife 4, e06205. doi: 10.7554/eLife.06205
Nacev, B. A., Feng, L., Bagert, J. D., Lemiesz, A. E., Gao, J., Soshnev, A. A., et al. (2019). The expanding landscape of 'oncohistone' mutations in human cancers. Nature 567, 473-478. doi: 10.1038/s41586-019-1038-1

Nimura, K., Ura, K., Shiratori, H., Ikawa, M., Okabe, M., Schwartz, R. J., et al. (2009). A histone H3 lysine 36 trimethyltransferase links Nkx2-5 to WolfHirschhorn syndrome. Nature 460, 287-291. doi: 10.1038/nature08086

Osipovich, A. B., Gangula, R., Vianna, P. G., and Magnuson, M. A. (2016). Setd5 is essential for mammalian development and the co-transcriptional regulation of histone acetylation. Development 143 (24), 4595-4607. doi: 10.1242/ dev.141465

Pai, C.-C., Deegan, R. S., Subramanian, L., Gal, C., Sarkar, S., Blaikley, E. J., et al. (2014). A histone H3K36 chromatin switch coordinates DNA double-strand break repair pathway choice. Nat. Commun. 5, 4091. doi: 10.1038/ ncomms5091

Papillon-Cavanagh, S., Lu, C., Gayden, T., Mikael, L. G., Bechet, D., Karamboulas, C., et al. (2017). Impaired H3K36 methylation defines a subset of head and neck squamous cell carcinomas. Nat. Genet. 49, 180-185. doi: $10.1038 / \mathrm{ng} .3757$

Parenti, I., Teresa-Rodrigo, M. E., Pozojevic, J., Ruiz Gil, S., Bader, I., Braunholz, D., et al. (2017). Mutations in chromatin regulators functionally link Cornelia de Lange syndrome and clinically overlapping phenotypes. Hum. Genet. 136, 307-320. doi: 10.1007/s00439-017-1758-y

Pfister, S. X., Ahrabi, S., Zalmas, L.-P., Sarkar, S., Aymard, F., Bachrati, C. Z., et al. (2014). SETD2-dependent histone H3K36 trimethylation is required for homologous recombination repair and genome stability. Cell Rep. 7, 20062018. doi: 10.1016/j.celrep.2014.05.026

Poulin, M. B., Schneck, J. L., Matico, R. E., McDevitt, P. J., Huddleston, M. J., Hou, W., et al. (2016). Transition state for the NSD2-catalyzed methylation of histone H3 lysine 36. Proc. Natl. Acad. Sci. 113, 1197 LP- 1201. doi: 10.1073/ pnas. 1521036113

Pradeepa, M. M., Sutherland, H. G., Ule, J., Grimes, G. R., and Bickmore, W. A. (2012). Psip1/Ledgf p52 binds methylated histone H3K36 and splicing factors and contributes to the regulation of alternative splicing. PloS Genet. 8, e1002717. doi: 10.1371/journal.pgen.1002717

Qiao, Q., Li, Y., Chen, Z., Wang, M., Reinberg, D., and Xu, R.-M. (2011). The structure of NSD1 reveals an autoregulatory mechanism underlying histone H3K36 methylation. J. Biol. Chem. 286, 8361-8368. doi: 10.1074/ jbc.M110.204115

Rauch, A., Wieczorek, D., Graf, E., Wieland, T., Endele, S., Schwarzmayr, T., et al. (2012). Range of genetic mutations associated with severe non-syndromic sporadic intellectual disability: an exome sequencing study. Lancet 380, $1674-$ 1682. doi: 10.1016/S0140-6736(12)61480-9

Rayasam, G. V., Wendling, O., Angrand, P. O., Mark, M., Niederreither, K., Song, L., et al. (2003). NSD1 is essential for early post-implantation development and has a catalytically active SET domain. EMBO J. 22, 3153 3163. doi: $10.1093 /$ emboj/cdg288

Sankaran, S. M., Wilkinson, A. W., Elias, J. E., and Gozani, O. (2016). A PWWP domain of histone-Lysine N-methyltransferase NSD2 binds to dimethylated Lys-36 of histone $\mathrm{H} 3$ and regulates NSD2 function at chromatin. J. Biol. Chem. 291 (16), 8465-8474. doi: 10.1074/jbc.M116.720748

Sarimski, K., and Psychologist, C. (2003). Behavioural and emotional characteristics in children with Sotos syndrome and learning disabilities. Dev. Med. Child Neurol. 45, 172-178. doi: 10.1111/j.1469-8749.2003.tb00926.x

Sessa, A., Fagnocchi, L., Mastrototaro, G., Massimino, L., Zaghi, M., Indrigo, M., et al. (2019). SETD5 regulates chromatin methylation state and preserves global transcriptional fidelity during brain development and neuronal wiring. Neuron 104, 271-289e13. doi: 10.1016/j.neuron.2019.07.013

Shin, J., Ming, G., and Song, H. (2014). Decoding neural transcriptomes and epigenomes via high-throughput sequencing. Nat. Neurosci. 17, 1463-1475. doi: $10.1038 / \mathrm{nn} .3814$

Stec, I., Wright, T. J., van Ommen, G.-J. B., de Boer, P. A. J., van Haeringen, A., Moorman, A. F. M., et al. (1998). WHSC1, a $90 \mathrm{~kb}$ SET domain-containing gene, expressed in early development and homologous to a Drosophila Dysmorphy gene maps in the wolf-hirschhorn syndrome critical region and is fused to IgH in t(1;14) Multiple Myeloma. Hum. Mol. Genet. 7, 1071-1082. doi: $10.1093 / \mathrm{hmg} / 7.7 .1071$

Stec, I., van Ommen, G.-J. B., and den Dunnen, J. T. (2001). WHSC1L1, on Human Chromosome 8p11.2, closely resembles WHSC1 and maps to a 
duplicated region shared with 4p16.3. Genomics 76, 5-8. doi: 10.1006/ geno.2001.6581

Sudo, G., Kagawa, T., Kokubu, Y., Inazawa, J., and Taga, T. (2016). Increase in GFAP-positive astrocytes in histone demethylase GASC1/KDM4C/JMJD2C hypomorphic mutant mice. Genes Cells 21 (3), 218-225. doi: 10.1111/gtc.12331

Szczałuba, K., Brzezinska, M., Kot, J., Rydzanicz, M., Walczak, A., Stawiński, P., et al. (2016). SETD5 loss-of-function mutation as a likely cause of a familial syndromic intellectual disability with variable phenotypic expression. Am. J. Med. Genet. Part A. 170, 2322-2327. doi: 10.1002/ajmg.a.37832

Tanaka, Y., Katagiri, Z., Kawahashi, K., Kioussis, D., and Kitajima, S. (2007). Trithorax-group protein ASH1 methylates histone H3 lysine 36. Gene 397, 161-168. doi: 10.1016/j.gene.2007.04.027

Tatton-Brown, K., Seal, S., Ruark, E., Harmer, J., Ramsay, E., del Vecchio Duarte, S., et al. (2014). Mutations in the DNA methyltransferase gene DNMT3A cause an overgrowth syndrome with intellectual disability. Nat. Genet. 46, 385. doi: 10.1038/ng.2917

Tatton-Brown, K., Zachariou, A., Loveday, C., Renwick, A., Mahamdallie, S., Aksglaede, L., et al. (2018). The Tatton-Brown-Rahman Syndrome: a clinical study of 55 individuals with de novo constitutive DNMT3A variants [version 1; peer review: 3 approved]. Wellcome Open Res. 3. doi: 10.12688/wellcomeopenres.14430.1

Tsukada, Y., Fang, J., Erdjument-Bromage, H., Warren, M. E., Borchers, C. H., Tempst, P., et al. (2006). Histone demethylation by a family of JmjC domaincontaining proteins. Nature 439, 811-816. doi: 10.1038/nature04433

Turner, B. M. (2007). Defining an epigenetic code. Nat. Cell Bio. 9 (1), 2-6. doi: 10.1038/ncb0107-2

Vermeulen, M., Eberl, H. C., Matarese, F., Marks, H., Denissov, S., Butter, F., et al. (2010). Quantitative interaction proteomics and genome-wide profiling of epigenetic histone marks and their readers. Cell 142, 967-980. doi: 10.1016/ j.cell.2010.08.020

Waggoner, D. J., Raca, G., Welch, K., Dempsey, M., Anderes, E., Ostrovnaya, I., et al. (2005). NSD1 analysis for Sotos syndrome: insights and perspectives from the clinical laboratory. Genet. Med. 7, 524-533. doi: 10.1097/01.GIM.000 0178503.15559.d3

Wagner, E. J., and Carpenter, P. B. (2012). Understanding the language of Lys36 methylation at histone H3. Nat. Rev. Mol. Cell Biol. 13, 115-126. doi: 10.1038/ nrm3274

Wang, G. G., Cai, L., Pasillas, M. P., and Kamps, M. P. (2007). NUP98-NSD1 links H3K36 methylation to Hox-A gene activation and leukaemogenesis. Nat. Cell Biol. 9, 804-812. doi: 10.1038/ncb1608
Weinberg, D. N., Papillon-Cavanagh, S., Chen, H., Yue, Y., Chen, X., Rajagopalan, K. N., et al. (2019). The histone mark H3K36me2 recruits DNMT3A and shapes the intergenic DNA methylation landscape. Nature 573, 281-286. doi: 10.1038/s41586-019-1534-3

Whetstine, J. R., Nottke, A., Lan, F., Huarte, M., Smolikov, S., Chen, Z., et al. (2006). Reversal of histone lysine trimethylation by the JMJD2 family of histone demethylases. Cell 125, 467-481. doi: 10.1016/j.cell.2006.03.028

Wu, H., Zeng, H., Lam, R., Tempel, W., Amaya, M. F., Xu, C., et al. (2011). Structural and histone binding ability characterizations of human PWWP domains. PloS One 6, e18919. doi: 10.1371/journal.pone.0018919

Xiao, T., Hall, H., Kizer, K. O., Shibata, Y., Hall, M. C., Borchers, C. H., et al. (2003). Phosphorylation of RNA polymerase II CTD regulates $\mathrm{H} 3$ methylation in yeast. Genes Dev. 17, 654-663. doi: 10.1101/gad.1055503

Yamaguchi, Y., Takagi, T., Wada, T., Yano, K., Furuya, A., Sugimoto, S., et al. (1999). NELF, a multisubunit complex containing RD, cooperates with DSIF to repress RNA polymerase II elongation. Cell 97, 41-51. doi: 10.1016/s0092-8674 (00)80713-8

Yu, Y., Chen, J., Gao, Y., Gao, J., Liao, R., Wang, Y., et al. (2016). Quantitative profiling of combinational K27/K36 modifications on histone $\mathrm{H} 3$ variants in mouse organs. J. Proteome Res. 15 (3), 1070-1079. doi: 10.1021/ acs.jproteome.5b01164

Zee, B. M., Levin, R. S., DiMaggio, P. A., and Garcia, B. A. (2010). Global turnover of histone post-translational modifications and variants in human cells. Epigenet. Chromatin. 3 (1), 22. doi: 10.1186/1756-8935-3-22

Zhang, Y., Xie, S., Zhou, Y., Xie, Y., Liu, P., Sun, M., et al. (2014). H3K36 histone methyltransferase Setd2 is required for murine embryonic stem cell differentiation toward endoderm. Cell Rep. 8, 1989-2002. doi: 10.1016/ j.celrep.2014.08.031

Conflict of Interest: The authors declare that the research was conducted in the absence of any commercial or financial relationships that could be construed as a potential conflict of interest.

Copyright (c) 2020 Zaghi, Broccoli and Sessa. This is an open-access article distributed under the terms of the Creative Commons Attribution License (CC BY). The use, distribution or reproduction in other forums is permitted, provided the original author $(s)$ and the copyright owner(s) are credited and that the original publication in this journal is cited, in accordance with accepted academic practice. No use, distribution or reproduction is permitted which does not comply with these terms. 